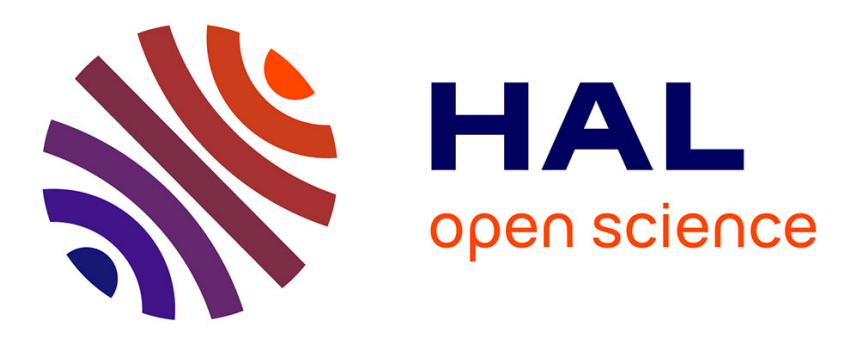

\title{
Applicability of natural abundance 33S solid-state NMR to cement chemistry
}

Jean-Baptiste d'Espinose, Fabien Barberon, Bruno Bresson, Philippe

Fonollosa, Hélène Zanni, Vladimir E Fedorov, Nikolai G Naumov, Zhehong Gan

\section{To cite this version:}

Jean-Baptiste d'Espinose, Fabien Barberon, Bruno Bresson, Philippe Fonollosa, Hélène Zanni, et al.. Applicability of natural abundance 33S solid-state NMR to cement chemistry. Cement and Concrete Research, 2006, 36 (9), pp.1781-1783. 10.1016/j.cemconres.2006.05.023 . hal-03130287

\section{HAL Id: hal-03130287 https://hal.science/hal-03130287}

Submitted on 23 Feb 2021

HAL is a multi-disciplinary open access archive for the deposit and dissemination of scientific research documents, whether they are published or not. The documents may come from teaching and research institutions in France or abroad, or from public or private research centers.
L'archive ouverte pluridisciplinaire HAL, est destinée au dépôt et à la diffusion de documents scientifiques de niveau recherche, publiés ou non, émanant des établissements d'enseignement et de recherche français ou étrangers, des laboratoires publics ou privés. 


\title{
Applicability of natural abundance ${ }^{33} \mathrm{~S}$ solid-state NMR to cement chemistry
}

\author{
Jean-Baptiste d'Espinose de Lacaillerie ${ }^{\mathrm{a}, *}$, Fabien Barberon ${ }^{\mathrm{a}}$, Bruno Bresson ${ }^{\mathrm{a}}$, \\ Philippe Fonollosa ${ }^{\mathrm{a}, \mathrm{d}}$, Hélène Zanni ${ }^{\mathrm{a}}$, Vladimir E. Fedorov ${ }^{\mathrm{b}}$, Nikolai G. Naumov ${ }^{\mathrm{b}}$, Zhehong Gan ${ }^{\mathrm{c}}$

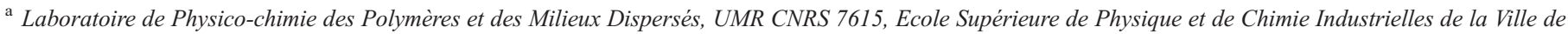 \\ Paris, 10 rue Vauquelin, 75231 Paris Cedex 05, France \\ ${ }^{\mathrm{b}}$ Nikolaev Institute of Inorganic Chemistry, Russian Academy of Sciences, 3, Acad. Lavrentiev Prospect, 630090 Novosibirsk, Russia \\ c National High Magnetic Field Laboratory, 1800 East Paul Dirac Drive, Tallahassee, FL 32310, USA \\ d Lafarge L.C.R., 95, rue du Montmurier, BP 15, 38291 St Quentin Fallavier Cedex, France
}

Received 18 April 2006; accepted 29 May 2006

\begin{abstract}
With the development of high-magnetic field spectrometers, ${ }^{33} \mathrm{~S}$ solid-state NMR is now clearly feasible but remains complex, especially considering the low sensitivity of ${ }^{33} \mathrm{~S}$ NMR. This communication briefly explores the potential of ${ }^{33} \mathrm{~S}$ NMR in the field of cement chemistry. Based on a few significant examples such as the one of ettringite, whose sulfur NMR spectrum is reported here for the first time, it appears that ${ }^{33} \mathrm{~S}$ solid-state NMR might be able to distinguish between the sulphates present in a cement paste taking advantage of both the chemical shift and the quadrupolar interaction.
\end{abstract}

(C) 2006 Elsevier Ltd. All rights reserved.

Keywords: Sulfate; Sulphate; ${ }^{33}$ S NMR

\section{Introduction}

Sulphate solubility, chemistry, and reactivity are among the key elements needed for understanding the durability of cementicious materials. Several processes of the deterioration of cement matrices, such as delayed ettringite formation, can be interpreted in terms of sulphate-phase stability and sulphate ions' interactions with hydrates. Consequently, the development of spectroscopies able to probe quantitatively the local environment of sulphates inside a cement matrix appear as desirable experimental complements to theoretical attempts to model the evolution of cementitious materials with temperature and time. In particular, Raman spectroscopy has recently received attention as a tool able to distinguish the sulphate species according to the split and shift of the sulphate group vibration modes [1]. However, Raman spectroscopy of cement samples remains difficult to operate in a quantitative manner due to strong absorption and fluorescence at the Raman frequency range by the matrix. Moreover, significant overlap can be expected in complex hydrated materials. By comparison, NMR has the potential to provide quantitative information on the local environment of chemical groups regardless of the crystallinity and the nature of the matrix (provided it is diamagnetic). For this reason ${ }^{29} \mathrm{Si}$ and ${ }^{27} \mathrm{Al}$ NMR have been extensively used to study cement pastes. However, except for a few remarkable studies $[2,3]$, until recently, the literature has remained silent on sulfur NMR. Indeed, ${ }^{33} \mathrm{~S}$ NMR appeared out of reach in the solid state, mainly because of its low resonance frequency and reduced sensitivity due to its low gyromagnetic ratio $(\gamma)\left(2.055 \times 10^{7} \mathrm{rad} \mathrm{T}^{-1} \mathrm{~s}^{-1}\right.$, that is less than $10 \%$ of the one of proton) and low natural abundance $(0.76 \%)$ [4]. As highfield $(>17 \mathrm{~T})$ spectrometers are now being serviced worldwide, the limitations associated with the low $\gamma$ are expected to vanish, and it has been recognized that it is now time to revisit the potential of ${ }^{33} \mathrm{~S}$ NMR to identify local structures of sulphides [5], sulphites [6], and sulphates [6,7]. Nevertheless, solid-state ${ }^{33} \mathrm{~S}$ NMR is still clearly in its infancy as only one published study has gone beyond demonstrating feasibility and has actually applied the technique [6]. In order to explore more 
specifically this new potential in chemical systems relevant to cement science, we thus report and discuss here the feasibility of one-pulse, natural abundance ${ }^{33} \mathrm{~S}$ solid-state MAS NMR spectra obtained at $63.6 \mathrm{MHz}(19.6 \mathrm{~T})$ for three bulk compounds representative of sulphate speciation in cement paste: magnesium sulphate, gypsum, and ettringite.

\section{Materials and methods}

\subsection{Materials}

$\mathrm{Cs}_{2} \mathrm{SO}_{4}$ and $\mathrm{MgSO}_{4}$ were purchased from Aldrich. Three gypsum $\left(\mathrm{CaSO}_{4} \cdot 2 \mathrm{H}_{2} \mathrm{O}\right)$ samples were studied. Synthetic $90 \%+$ enriched ${ }^{33} \mathrm{~S} \mathrm{CaSO}_{4} \cdot 2 \mathrm{H}_{2} \mathrm{O}$ was precipitated from an enriched sulphate solution obtained by the oxidation of elemental ${ }^{33} \mathrm{~S}$ with bromine. Reagent grade synthetic natural abundance ${ }^{33} \mathrm{~S}$ $\mathrm{CaSO}_{4} \cdot 2 \mathrm{H}_{2} \mathrm{O}$ was purchased from Aldrich. Mineral technical grade was courtesy of Soletanche-Bachy (France). Ettringite $\left(\mathrm{Ca}_{6} \mathrm{Al}_{2}\left(\mathrm{SO}_{4}\right)_{3}(\mathrm{OH})_{12} \cdot 26 \mathrm{H}_{2} \mathrm{O}\right)$ was courtesy of Dr. Divet (LCPC, France). The samples were ground to powder when necessary and used as such. XRD patterns were verified prior to NMR using a Philips X'Pert MPD diffractometer at the $\mathrm{Cu} \mathrm{K}_{\alpha}$ radiation.
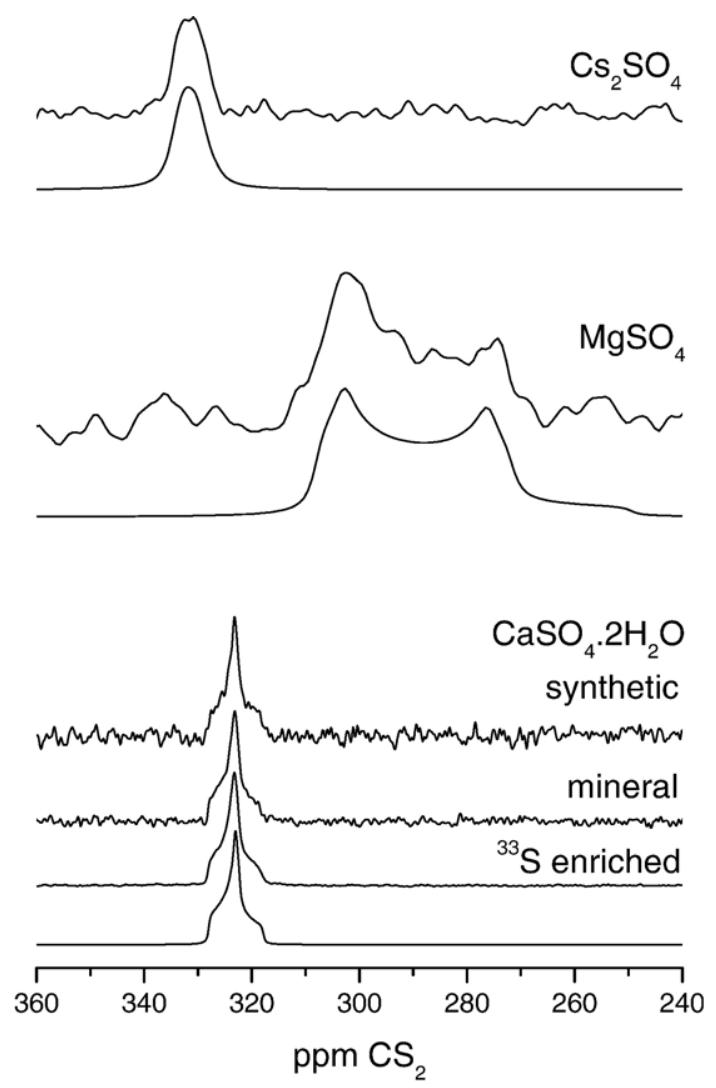

Fig. 1. Powder ${ }^{33} \mathrm{~S}$ MAS NMR of sulphates. The one-pulse spectra were obtained at $63.6 \mathrm{MHz}(19.6 \mathrm{~T})$. The traces below the spectra are second-order quadrupolar models of the central transition adjusted to the experimental data using DMFIT and the NMR parameters reported in Table 1. $\mathrm{Cs}_{2} \mathrm{SO}_{4}: 752$ scans, 10 s recycle time. $\mathrm{MgSO}_{4}: 30000$ scans, $200 \mathrm{~ms}$ recycle time. $\mathrm{CaSO}_{4} \cdot 2 \mathrm{H}_{2} \mathrm{O}$ natural abundance: 1000 scans, 20 s recycle time. $\mathrm{CaSO}_{4} \cdot 2 \mathrm{H}_{2} \mathrm{O}{ }^{33} \mathrm{~S}$ enriched: 16 scans, 20 s recycle time.
Table 1

${ }^{33} \mathrm{~S}$ NMR parameters from lineshape fitting

\begin{tabular}{lllll}
\hline Compound & $C_{\mathrm{Q}}(\mathrm{MHz})$ & $\eta_{\mathrm{Q}}$ & $\delta_{\text {iso }}(\mathrm{ppm})$ & $\begin{array}{l}\text { Line broadening } \\
(\mathrm{Hz})\end{array}$ \\
\hline $\mathrm{Cs}_{2} \mathrm{SO}_{4}$ & & & & 200 \\
$\mathrm{MgSO}_{4}$ & 0.8 & 0.45 & 335 & 200 \\
$\mathrm{CaSO}_{4} \cdot 2 \mathrm{H}_{2} \mathrm{O}$ & 2.1 & 0.15 & 315 & 30 \\
$\mathrm{Ca}_{6}\left[\mathrm{Al}(\mathrm{OH})_{6}\right]_{2}\left(\mathrm{SO}_{4}\right)_{3} \cdot 26 \mathrm{H}_{2} \mathrm{O}$ & 0.7 & 1.0 & 328 & 50 \\
\hline
\end{tabular}

\subsection{MAS NMR}

Magic angle spinning nuclear magnetic resonance (MAS NMR) experiments were performed at $19.6 \mathrm{~T}$ on a Bruker DRX spectrometer in $4 \mathrm{~mm}$ zirconia rotors at the NHMFL in Tallahassee (USA). ${ }^{33} \mathrm{~S}(I=3 / 2)$ one-pulse experiments were performed at $63.6 \mathrm{MHz}$, spinning between 6 and $8 \mathrm{kHz}$. For a quadrupolar nucleus, it was necessary to selectively excite the central transition in order to remain quantitative. This was performed by applying a pulse whose length correspond to a tilt angle of less than $(2 I+1)$, namely $\pi / 4$ in the case of ${ }^{33} \mathrm{~S}(I=3 / 2)$. Consequently, the pulse duration was $2 \mu$ s for a radio-frequency magnetic field strength corresponding to a precession frequency of about $45 \mathrm{kHz}$. The spectral width was $40 \mathrm{kHz}$ with digital filtering. Numbers of acquisitions and recycle times for each sample are indicated in the relevant figure captions. The chemical shift was referred to the resonance of a $1 \mathrm{M} \mathrm{Cs}_{2} \mathrm{SO}_{4}$ aqueous solution, taken as a secondary reference at $333 \mathrm{ppm}$ from the primary standard of neat $\mathrm{CS}_{2}$. The central bands of the one-pulse spectra were fitted assuming a central transition second-order quadrupolar line shape using the DMFIT program [8].

\section{Results}

The natural abundance spectra of caesium $[3,6,7]$, magnesium [7], and calcium sulphates [3,7] have already been reported in the literature and our results are presented here for comparison purpose only (Fig. 1). Our results are in agreement with the ones of Wagler et al. [7]. The fitting of the spectra with second-order quadrupolar line shapes produced a satisfactory estimate of the NMR parameters (Table 1). Of importance to the applicability to cement science, it must be noted that although high fields increase the signal-to-noise ratio due to a simultaneous increase of sensitivity and decrease of the quadrupolar line width, the overall sensitivity remained poor due to the low natural abundance of ${ }^{33} \mathrm{~S}$. The acquisition of the spectrum of bulk gypsum with a signal to noise ratio of 10 took a total of $8 \mathrm{~h}$. Moreover, sulphate groups are about twenty times less abundant in Portland cement than in gypsum. Considering that the signal-to-noise ratio scales with the square of the number of scans, it follows that the acquisition of a signal of same quality in Portland cement would require 133 days. This is obviously impractical. Conversely, the acquisition of the spectrum of the ${ }^{33} \mathrm{~S}$ enriched gypsum sample provided a signal to noise over 50 in $5 \mathrm{~min}$. Obviously, ${ }^{33} \mathrm{~S}$ NMR is not adapted to the characterization of field samples, and, without isotopic enrichment, would be limited to samples with exceptionally high sulphate contents or to fundamental studies of a chemical subsystem equilibrium. 


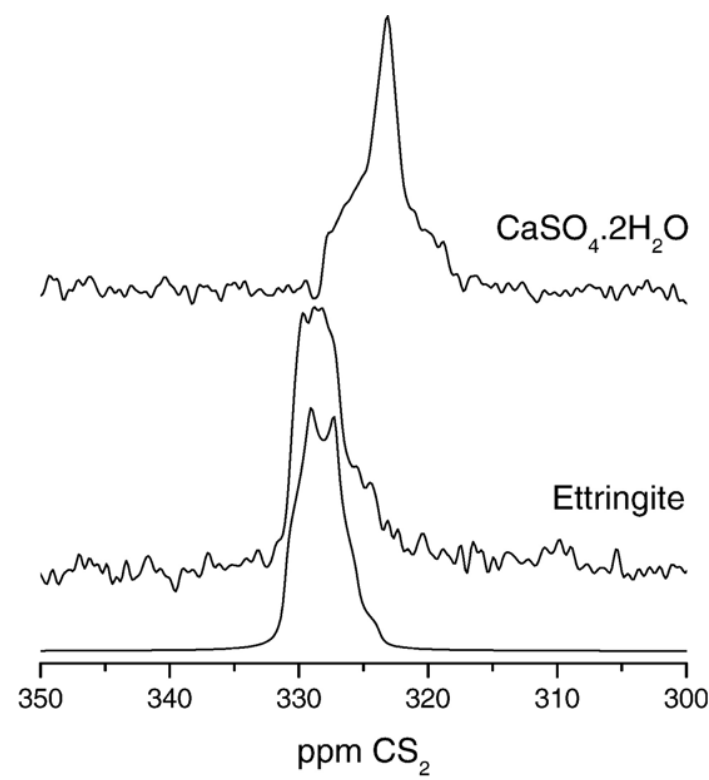

Fig. 2. Comparison of the powder ${ }^{33} \mathrm{~S}$ MAS NMR spectra of ettringite (70000 scans, $1 \mathrm{~s}$ recycle time) and gypsum (same as Fig. 1).

Besides sensitivity, to probe the potential of sulphur NMR, it is necessary to address its ability to discriminate between different sulphate speciations. On the one hand, the chemical environment of the sulphur atom in a sulphate group is not expected to vary greatly in one sulphate or another from the expected distorted tetrahedron of the sulphate anion. Indeed, all the sulphates studied here presented similar isotropic chemical shifts within $10 \mathrm{ppm}$. On the other hand, however, the secondorder quadrupolar line shape depends not on the electron density around the nucleus but on the electrical field gradient. It is therefore a very sensitive probe of the electronic symmetry around the nucleus, and thus indirectly of the lattice structure. Thus, for quadrupolar nuclei, the line shape often provides a clearer signature of a particular chemical occurrence than the chemical shift, and it can be related unequivocally to a particular structure through ab initio DFT-based calculations [9]. This conjecture was verified for cement chemical systems by comparing, as an example, the spectrum of the trisulphoaluminate ettringite with the one of gypsum (Fig. 2). The line shape of ettringite was significantly distinctive and clearly different from the one of gypsum. In particular, the symmetry of the sulphate group is not as severely distorted in ettringite [10] as in gypsum [11]. This translated in an asymmetry parameter $(\eta)$ reduced from 1 in gypsum to circa 0.4 in ettringite and thereby in significantly different line shapes. The two sulphates could thus be distinguished despite having close isotropic chemical shifts: $328 \mathrm{ppm}$ for gypsum and $331 \mathrm{ppm}$ for ettringite. In this case, the quadrupolar interaction spread apart the maxima of each resonance by about $15 \mathrm{ppm}$ in the present field of $19.6 \mathrm{~T}$. There is a thus good prospect that it might be possible to distinguish sulphates in complex cement samples by ${ }^{33} \mathrm{~S}$ solidstate NMR at high fields.

\section{Conclusion}

Despite the low natural abundance of ${ }^{33} \mathrm{~S}$, working at high field provided enough sensitivity to collect spectra in natural abundance for bulk compounds in a reasonable time. It is however clear that dilution of the sulphate in cements (typical values are less than $3 \% \mathrm{w} / \mathrm{w} \mathrm{SO}_{3}$ in CEM I Portland cement) will have to be compensated by enrichment if one intends to study cementitious matrices.

Despite this limitation, comparison of the gypsum and ettringite ${ }^{33} \mathrm{~S}$ MAS NMR line shapes gave strong hope that the ${ }^{33} \mathrm{~S}$ signature of sulphate groups will allow quantitative analysis of sulphate mineralogy in cement-related chemical systems. In that case, it might prove a useful complement to XRD or vibrational spectroscopy.

\section{References}

[1] S.S. Potgieter-Vermaak, J.H. Potgieter, R. Van Grieken, Cem. Concr. Res. 36 (2006) 656-662.

[2] T.J. Bastow, S.N. Stuart, Phys. Status Solidi A 145 (1988) 719-728.

[3] H. Eckert, J.P. Yesinowski, J. Am. Chem. Soc. 108 (1986) 2140-2146.

[4] M.E. Smith, in: J.W. Emsley, T.C. Farrar, B.C. Gerstein, A. McDermott (Eds.), Advances in NMR, vol. 9, Wiley, Chichester, 2002, pp. 607-620.

[5] T.A. Wagler, W.A. Daunch, P.L. Rinaldi, A.R. Palmer, J. Magn. Reson. 161 (2003) 191-197.

[6] S. Couch, A.P. Howes, S.C. Kohn, M.E. Smith, Solid State Nucl. Magn. Reson. 26 (2004) 203-208.

[7] T.A. Wagler, W.A. Daunch, M. Panzner, W.J. Youngs, P.L. Rinaldi, J. Magn. Reson. 170 (2004) 336-344.

[8] D. Massiot, F. Fayon, M. Capron, I. King, S. Le Calve, B. Alonso, J.O. Durand, B. Bujoli, Z.H. Gan, G. Hoatson, Magn. Reson. Chem. 40 (2002) $70-76$.

[9] J.B. d'Espinose de Lacaillerie, F. Barberon, K.V. Romanenko, O.B. Lapina, L. Le Polles, R. Gautier, Z.H. Gan, J. Phys. Chem., B 109 (2005) 14033-14042.

[10] M.R. Hartman, R. Berliner, Cem. Concr. Res. 36 (2006) 364-370.

[11] B.F. Pedersen, D. Semmingsen, Acta Crystallogr., B Struct. Sci. 38 (1982) 1074-1077. 